FERNANDES, C.; ARAÚJO, J.A.C.; CORÁ, J.E. Impacto de quatro substratos e parcelamento da fertirrigação na produção de tomate sob cultivo protegido. Horticultura Brasileira, Brasília, v. 20, n. 4, p. 559-563, dezembro 2002.

\title{
Impacto de quatro substratos e parcelamento da fertirrigação na produ- ção de tomate sob cultivo protegido
}

\author{
Carolina Fernandes ${ }^{1}$; Jairo A. C. Araújo ${ }^{2}$; José E. Corá ${ }^{2}$ \\ ${ }^{1}$ Aluna de Doutorado da UNESP, Jaboticabal; ${ }^{2}$ UNESP, Via de acesso Prof. Paulo Donato Castellane, s/n, 14.884-900 Jaboticabal, SP. \\ E-mail: carol@fcav.unesp.br
}

\section{RESUMO}

Analisou-se a produção do tomateiro, híbrido longa vida Carmen, cultivado em quatro substratos, com fertirrigação semanal e duas vezes por semana. O delineamento experimental utilizado foi blocos casualizados, em esquema fatorial $4 \times 2$ (quatro substratos e duas formas de fertirrigação), em quatro repetições. Os substratos testados foram: $\mathrm{S}_{1}=$ areia fina $(0,250-0,105 \mathrm{~mm}) ; \mathrm{S}_{2}=1 / 2$ areia fina $+1 / 2$ bagaço de cana-de-açúcar; $S_{3}=1 / 2$ areia fina $+1 / 2$ casca de amendoim moída (passada em peneira com abertura de 7 x 18 $\mathrm{mm})$ e $\mathrm{S}_{4}=1 / 3$ areia fina $+1 / 3$ bagaço de cana-de-açúcar $+1 / 3$ casca de amendoim moída. As fertirrigações avaliadas foram: $F_{1}=$ fertirrigação realizada uma vez por semana, com aplicação da quantidade total de nutrientes $\mathrm{e}, \mathrm{F}_{2}=$ fertirrigação realizada duas vezes por semana, com aplicação da metade da quantidade total de nutrientes, demandada por semana, em cada vez. A quantidade de nutrientes, em $\mathrm{m} \mathrm{L} \mathrm{L}^{-1}$, fornecida por meio de fertirrigação, foi: $200 \mathrm{de}$ nitrogênio, 60 de fósforo, 350 de potássio, 206 de cálcio, 60 de magnésio, 150 de enxofre, 0,50 de boro, 0,10 de cobre, 2 de ferro, 0,75 de manganês, 0,10 de zinco e 0,01 de molibdênio. A dotação hídrica foi realizada em função dos dados obtidos em um tanque classe A, localizado no centro da casa de vegetação. Avaliou-se a altura das plantas, o número de cachos e de frutos por planta, o peso individual do fruto e a produção por planta. Os dados foram submetidos à análise de variância e as médias foram comparadas pelo teste de Tukey, ao nível de $5 \%$ de probabilidade. Verificou-se que a fertirrigação realizada duas vezes por semana, suprindo a demanda total de nutrientes da semana, resultou em consideráveis melhorias de produção. Os substratos utilizados, com exceção do substrato $\mathrm{S}_{2}$, apresentaram potencial de uso para o cultivo do tomateiro em ambiente protegido.

Palavras-chave: Lycopersicon esculentum, cultivo sem solo, solução nutritiva, areia, bagaço de cana-de-açúcar, casca de amendoim.

\section{ABSTRACT}

Impact of four substrates and fertigation parceling on tomato yield in greenhouse conditions

The experiment was carried out at the UNESP in Jaboticabal (Brazil). The tomato, long-life hybrid cv. Carmen, was grown in four substrates with fertigation applied weekly and twice a week in greenhouse conditions. The experimental design was a complete randomized block, with a factorial array of $4 \times 2$ (four substrates and two forms of fertigation), with four replications. The substrates used were: $S_{1}=$ fine sand $(0.250-0.105 \mathrm{~mm}) ; S_{2}=1 / 2$ fine sand $+1 /$ 2 crushed sugar-cane; $S_{3}=1 / 2$ fine sand $+1 / 2$ ground peanut bark (screened by $7 \times 18 \mathrm{~mm}$ ); $\mathrm{S}_{4}=1 / 3$ fine sand $+1 / 3$ crushed sugarcane $+1 / 3$ ground peanut bark. The fertigations were: $F_{1}=$ total amount of nutrients applied, once a week and $\mathrm{F}_{2}=$ half of the total amount applied twice a week. The amount of nutrients, in $\mathrm{mg} \mathrm{L}^{-1}$, were: 200 of nitrogen, 60 of phosphorus, 350 of potassium, 206 of calcium, 60 of magnesium, 150 of sulphur, 0.50 of boron, 0.10 of copper, 2 of iron, 0.75 of manganese, 0.10 of zinc and 0.01 of molybdenum. The hydric dotation was realized based upon water evaporation in a class A pan, located at the center of the greenhouse. Plant height, number of bunches and fruits per plant, fruit weight and yield per plant were measured. The data were submitted to the variance analysis and the averages were compared by the test of Tukey, at the level of 5\% of probability. The highest yield was obtained when the fertigation was applied twice a week. The results showed that the substrates $\mathrm{S}_{1}, \mathrm{~S}_{3}$ and $\mathrm{S}_{4}$ can be used for tomate growth in greenhouse conditions.

Keywords: Lycopersicon esculentum, soilless growth, nutrient solution, sand, crushed sugar-cane, peanut bark.

\section{(Recebido para publicação em 13 de novembro de 2000 e aceito em 20 de maio de 2002)}

$\mathrm{O}$ cultivo do tomateiro em ambiente protegido tornou-se muito difundido na região Sudeste, principalmente no estado de São Paulo, importante centro produtor de hortaliças do Brasil. Esta técnica de cultivo advém da necessidade de fornecer ao consumidor produtos in natura de boa qualidade durante todo o ano.

O cultivo de plantas em ambiente protegido, geralmente, é realizado no solo. Porém, com o decorrer do tempo, em conseqüência da alta intensidade dos cultivos, têm sido observados vários problemas com reflexos negativos no rendimento das culturas. Destacam-se entre os principais, a ocorrência de pragas e fitopatógenos, que atacam o sistema radicular e, os desequilíbrios nutricionais, uma vez que os elementos minerais não absorvidos pelas raízes das plantas tendem a se acumular na camada superficial do solo, provocando a salinização e/ou antagonismo entre os nutrientes (Abak \& Celikel, 1994; Andriolo et al., 1997). O aparecimento dessas dificuldades levaram à busca de novas alternativas para o cultivo de es- pécies que exigem tratos culturais intensivos, como por exemplo, o tomate. Entre estas alternativas, destaca-se o cultivo de plantas em substratos com fertirrigação.

Um substrato agrícola deve guardar uma proporção adequada entre macro e microporos, favorecendo assim a atividade fisiológica das raízes e, conseqüentemente, o desenvolvimento das plantas. Segundo Gras, citado por Andriolo et al. (1997), os materiais utilizados como substratos devem ser inertes, combinar uma elevada capacidade de reten- 
ção de água com um potencial matricial relativamente baixo, ser abundantes, de baixo custo e isentos de pragas e fitopatógenos. Desta forma, qualquer material orgânico ou mineral com estas características, sem ser fitotóxico, apresenta potencial de uso como substrato agrícola.

A fertirrigação permite manter a disponibilidade de água e nutrientes próxima dos valores considerados ótimos ao crescimento e à produtividade da cultura. Sendo assim, a quantidade de nutrientes, parcelada ou não, deve ajustar-se às necessidades da cultura ao longo das fases de desenvolvimento. Ainda, o manejo da água deve evitar variações bruscas do potencial matricial do substrato, especialmente nos períodos de forte demanda evaporativa da atmosfera (Andriolo et al., 1997).

O presente trabalho teve como objetivo avaliar o comportamento do tomateiro cultivar Carmen, híbrido do tipo longa vida, em quatro substratos com duas formas de fertirrigação sob ambiente protegido.

\section{MATERIAL E MÉTODOS}

O experimento foi conduzido na UNESP em Jaboticabal, (SP). A altitude local é de $595 \mathrm{~m}$, com latitude de $21^{\circ} 15^{\prime} 22^{\prime}$ 'S e longitude de $48^{\circ} 18^{\prime} 58^{\prime \prime} \mathrm{W}$. O clima, segundo a classificação de Köppen, é do tipo subtropical com inverno seco (Cwa), com precipitação média anual de $1400 \mathrm{~mm}$, temperatura média anual de $22^{\circ} \mathrm{C}$ e umidade relativa média do ar de $70 \%$. A casa de vegetação, com orientação no sentido lesteoeste, foi construída em estrutura metálica, do tipo capela, com $4 \mathrm{~m}$ de pédireito, $30 \mathrm{~m}$ de comprimento e $10 \mathrm{~m}$ de largura, coberta com filme de polietileno transparente aditivado contra raios ultravioleta, com 100 micras de espessura e as laterais protegidas com telas de polipropileno preto $30 \%$.

O híbrido do tipo longa vida 'Carmen', segundo a empresa responsável, é bastante adaptado ao cultivo protegido e apresenta como características o crescimento indeterminado, bom pegamento de frutos sob ampla faixa de temperatura $\left(8 \mathrm{a} 40^{\circ} \mathrm{C}\right)$, frutos tipo caqui e resistentes a Fusarium raças 1 e 2, ví- rus do mosaíco e Verticilium raça 1. As mudas de tomate foram produzidas em bandejas de poliestireno, de acordo com a técnica rotineira na produção comercial, sendo o transplantio para os diferentes substratos realizado em 11/02/ 2000 , quando as mesmas se encontravam no estádio de seis folhas definitivas. A desbrota de todos os brotos axilares e a condução vertical da cultura em uma haste, através de fitilhos, foram realizadas semanalmente. A poda dos ponteiros foi realizada nas plantas que atingiram dois metros de altura. O raleio das flores e frutos não foi realizado. A colheita iniciou-se em 14/04 e estendeu-se até $02 / 06$, quando finalizou o ciclo da cultura.

O delineamento estatístico utilizado foi em blocos casualizados, com esquema fatorial $4 \times 2$ (quatro substratos e duas formas de fertirrigação), em quatro repetições. Os blocos foram instalados com o objetivo de minimizar qualquer diferença microclimática que pudesse ocorrer dentro do ambiente protegido. Sendo assim, cada quadrante da casa de vegetação correspondeu a um bloco. A composição dos quatro substratos avaliados, com os valores em base de volume, foram: $S_{1}=$ areia fina $(0,250-0,105 \mathrm{~mm}), S_{2}=1 / 2$ areia fina $+1 / 2$ bagaço de cana-de-açúcar, $\mathrm{S}_{3}=1$ / 2 areia fina $+1 / 2$ casca de amendoim moída (passada em peneira com abertura de $7 \times 18 \mathrm{~mm}$ ) e $\mathrm{S}_{4}=1 / 3$ areia fina $+1 / 3$ bagaço de cana-de-açúcar $+1 / 3$ casca de amendoim moída. As formas de fertirrigação testadas foram $\mathrm{F}_{1}=$ fertirrigação realizada uma vez por semana, às segundas-feiras, com aplicação da quantidade total de nutrientes e $\mathrm{F}_{2}=$ fertirrigação realizada duas vezes por semana, às segundas e quintas-feiras, com aplicação da metade da quantidade total de nutrientes em cada uma delas. A quantidade de nutrientes, em $\mathrm{mg} \mathrm{L}^{-1}$, fornecida através de fertirrigação, foi a recomendada por Moraes (1997): 200 de nitrogênio, 60 de fósforo, 350 de potássio, 206 de cálcio, 60 de magnésio, 150 de enxofre, 0,50 de boro, 0,10 de cobre, 2 de ferro, 0,75 de manganês, 0,10 de zinco e 0,01 de molibdênio. Avaliou-se a altura média das plantas, o número médio de cachos e de frutos por planta, o peso médio individual do fruto e a produção média por planta. Foi considerada área útil a correspondente às oito plantas centrais de cada parcela. Os dados foram submetidos à análise de variância e as médias foram comparadas pelo teste de Tukey, ao nível de 5\% de probabilidade.

A parcela experimental constituiuse de doze plantas espaçadas de $0,5 \mathrm{~m} \mathrm{e}$ conduzidas por 112 dias em substratos acondicionados em estruturas de cimento-amianto, tipo canaleta, com $6,5 \mathrm{~m}$ de comprimento, 0,49 $\mathrm{m}$ de largura útil e $0,18 \mathrm{~m}$ de profundidade. As canaletas foram dispostas de maneira que o espaçamento entre linhas fosse de 1,0 $\mathrm{m}$. Foram instaladas, como bordadura, duas linhas de plantas nas laterais da casa de vegetação. As canaletas foram instaladas com declividade aproximada de $2 \%$, a fim de assegurar a drenagem da solução nutritiva excedente. Para evitar que a solução nutritiva tivesse contato com o cimento-amianto, a parte interna das canaletas foi revestida com plástico preto. Os componentes dos substratos foram misturados de maneira uniforme e em seguida acondicionados nas canaletas até o seu completo preenchimento. Utilizou-se o sistema de irrigação localizada, com um gotejador ao lado do caule de cada planta. A lâmina de água aplicada em dois períodos, pela manhã e à tarde, foi a mesma para todos os tratamentos. A dotação hídrica foi calculada em função dos dados obtidos em um tanque Classe A, localizado no centro da casa de vegetação, considerando-se o coeficiente do tanque como 0,70 (Doorenbos \& Pruitt, 1976) e os coeficientes de cultura variáveis, em função do estádio de desenvolvimento do tomateiro (Doorenbos \& Kassan, 1979): 0,40 (da emergência até $10 \%$ do desenvolvimento vegetativo), 0,70 (do final do estádio anterior até o início do florescimento), 1,05 (do final do estádio anterior até o início da maturação) e 0,60 (do final do estádio anterior até a colheita).

Durante os primeiros trinta dias após o transplantio das mudas, a lâmina de água foi aplicada em função dos valores do tanque Classe A. Após este período, observou-se que as plantas apresentavam-se parcialmente murchas, nas horas mais quentes do dia, sendo este comportamento mais pronunciado no substrato composto somente de areia 
Impacto de quatro substratos e parcelamento da fertirrigação na produção de tomate sob cultivo protegido

Tabela 1. Altura média das plantas, número médio de cachos e frutos por planta, peso médio de frutos e produção média do tomateiro cultivado sob fertirrigação em cultivo protegido. Jaboticabal, FCAV/UNESP, 2000.

\begin{tabular}{lccccc}
\hline \multicolumn{1}{|c}{ Fertirrigação' } & $\begin{array}{c}\text { Altura } \\
(\mathbf{c m})\end{array}$ & $\begin{array}{c}\mathbf{N}^{\circ} \text { cachos } \\
\text { (planta) }\end{array}$ & $\begin{array}{c}\mathbf{N}^{\circ} \text { frutos } \\
\text { (planta) }\end{array}$ & $\begin{array}{c}\text { Peso de frutos } \\
\text { (g) }\end{array}$ & $\begin{array}{c}\text { Produção } \\
\text { (kg planta-1) }^{-1}\end{array}$ \\
\hline $\mathrm{F}_{1}$ & $98,45 \mathrm{~b}$ & $3,51 \mathrm{a}$ & $9,42 \mathrm{~b}$ & $92,85 \mathrm{a}$ & $0,93 \mathrm{~b}$ \\
$\mathrm{~F}_{2}$ & $104,43 \mathrm{a}$ & $3,73 \mathrm{a}$ & $11,51 \mathrm{a}$ & $92,03 \mathrm{a}$ & $1,08 \mathrm{a}$ \\
\hline C.V. $(\%)$ & 5,49 & 9,09 & 16,21 & 6,48 & 16,71 \\
\hline
\end{tabular}

${ }^{1} \mathrm{~F}_{1}=$ fertirrigação realizada uma vez por semana, com aplicação da quantidade total de nutrientes demandada semanalmente e $\mathrm{F}_{2}=$ fertirrigação realizada duas vezes por semana, com aplicação da metade da quantidade total de nutrientes em cada uma delas.

Médias seguidas da mesma letra, na coluna, não diferem estatisticamente entre si, pelo teste de Tukey, ao nível de 5\% de probabilidade.

Tabela 2. Altura média das plantas, número médio de cachos e frutos por planta, peso médio de frutos e produção média do tomateiro cultivado em quatro substratos diferentes em cultivo protegido. Jaboticabal, FCAV/UNESP, 2000.

\begin{tabular}{lccccc}
\hline \multicolumn{1}{c}{ Substratos $^{1}$} & $\begin{array}{c}\text { Altura } \\
\text { (cm) }\end{array}$ & $\begin{array}{c}\mathbf{N}^{\circ} \text { cachos } \\
\text { (planta) }\end{array}$ & $\begin{array}{c}\mathbf{N}^{\circ} \text { frutos } \\
\text { (planta) }\end{array}$ & $\begin{array}{c}\text { Peso de frutos } \\
\text { (g) }\end{array}$ & $\begin{array}{c}\text { Produção } \\
\text { (kg planta-1) }\end{array}$ \\
\hline $\mathrm{S}_{1}$ & $109,02 \mathrm{a}$ & $3,95 \mathrm{a}$ & $12,34 \mathrm{a}$ & $100,87 \mathrm{a}$ & $1,23 \mathrm{a}$ \\
$\mathrm{S}_{2}$ & $84,94 \mathrm{~b}$ & $2,47 \mathrm{~b}$ & $5,18 \mathrm{~b}$ & $67,05 \mathrm{~b}$ & $0,35 \mathrm{~b}$ \\
$\mathrm{~S}_{3}$ & $106,80 \mathrm{a}$ & $4,09 \mathrm{a}$ & $11,93 \mathrm{a}$ & $96,07 \mathrm{a}$ & $1,14 \mathrm{a}$ \\
$\mathrm{S}_{4}$ & $104,99 \mathrm{a}$ & $3,97 \mathrm{a}$ & $12,42 \mathrm{a}$ & $105,77 \mathrm{a}$ & $1,30 \mathrm{a}$ \\
\hline C.V. $(\%)$ & 5,49 & 9,09 & 16,21 & 6,48 & 16,71 \\
\hline
\end{tabular}

${ }^{1} \mathrm{~S}_{1}=$ areia fina; $\mathrm{S}_{2}=1 / 2$ areia fina $+1 / 2$ bagaço de cana-de açúcar; $\mathrm{S}_{3}=1 / 2$ areia fina $+1 / 2$ casca de amendoim moída e $\mathrm{S}_{4}=1 / 3$ areia fina $+1 / 3$ bagaço de cana-de-açúcar $+1 / 3$ casca de amendoim moída.

Médias seguidas da mesma letra, na coluna, não diferem estatisticamente entre si, pelo teste de Tukey, ao nível de $5 \%$ de probabilidade.

fina $\left(\mathrm{S}_{1}\right)$. Segundo Fernandes et al. (2000), a areia fina apresenta menor capacidade de retenção de água, quando comparada aos mesmos substratos utilizados neste experimento, fazendo com que a água disponível às plantas diminua rapidamente. Com o desenvolvimento da cultura, observou-se um aumento no período de murchamento. Assim, as plantas foram diariamente observadas e, ao constatar murchamento, aumentos de $20 \%$ da quantidade de água fornecida foram realizados. Na tentativa de acompanhar o potencial matricial dos substratos, aos 36 dias após o transplantio, foram instalados tensiômetros nas parcelas do substrato $\mathrm{S}_{1}$ e verificados valores de potencial matricial entre 24 e $40 \mathrm{KPa}$, sendo $75 \%$ das leituras com valores próximos a 40 KPa. De acordo com Silva \& Simão, citado por Marouelli et al. (1996), a faixa de tensão de água no solo em que se deve promover a irrigação da cultura do tomate está entre 30 e $100 \mathrm{KPa}$. Portanto, constatou-se que a cultura estava exigindo maior teor de umidade no substrato e, conseqüentemente, apresentava decréscimo da atividade fisiológica. A partir dos 59 dias após o transplantio, aplicou-se $150 \%$ acima da quantidade de água determinada inicialmente através dos dados do tanque Classe A. Nesta condição, verificou-se valores de potencial matricial próximos a $24 \mathrm{KPa}$ e não mais se observou murchamento das plantas.

\section{RESULTADOS E DISCUSSÃO}

A análise de variância não apresentou resultado significativo para a interação entre substratos e formas de fertirrigação, por isso os resultados foram discutidos separadamente.

As plantas que receberam a fertirrigação parcelada $\left(\mathrm{F}_{2}\right)$ apresentaram maior altura, maior número de frutos e maior produção, quando comparadas àquelas que receberam a fertirrigação uma vez por semana $\left(\mathrm{F}_{1}\right)$. Não foram observadas diferenças estatísticas significativas para o número de cachos por planta e o peso de frutos (Tabela 1). Embora os benefícios do parcelamento de adubação em cultivos no solo, principalmente para nitrogênio e potássio, sejam conhecidos, trabalhos que tratam de parcelamento da oferta de nutrientes, através de fertirrigação, para culturas conduzidas em substratos sob ambiente protegido, são escassos. Neste trabalho observou-se que o efeito benéfico do parcelamento da oferta de nutrientes também se fez presente nestas condições. Além do maior desenvolvimento vegetativo, o parcelamento da fertirrigação também pode ter induzido ao maior pegamento de frutos, uma vez que proporcionou maior número de frutos colhidos, sem ter levado à formação de um maior número de cachos por planta.

De maneira geral, as plantas conduzidas nos substratos $\mathrm{S}_{1}, \mathrm{~S}_{3}$ e $\mathrm{S}_{4}$ apresentaram, em média, maior altura, maior número de cachos por planta, maior número de frutos por planta, frutos mais pesados e maior produção, quando comparados aos mesmos parâmetros observados nas plantas desenvolvidas no substrato $\mathrm{S}_{2}$ (Tabela 2). As plantas conduzidas no substrato $\mathrm{S}_{2}$ apresentaram altura semelhante àquelas conduzidas nos demais substratos até os 20 dias após o transplantio (Figura 1). Entretanto, verifica-se que o desenvolvimento insatisfatório das plantas no substrato $S_{2}$, aos 40 e 60 dias após o transplantio, foi provavelmente influen- 


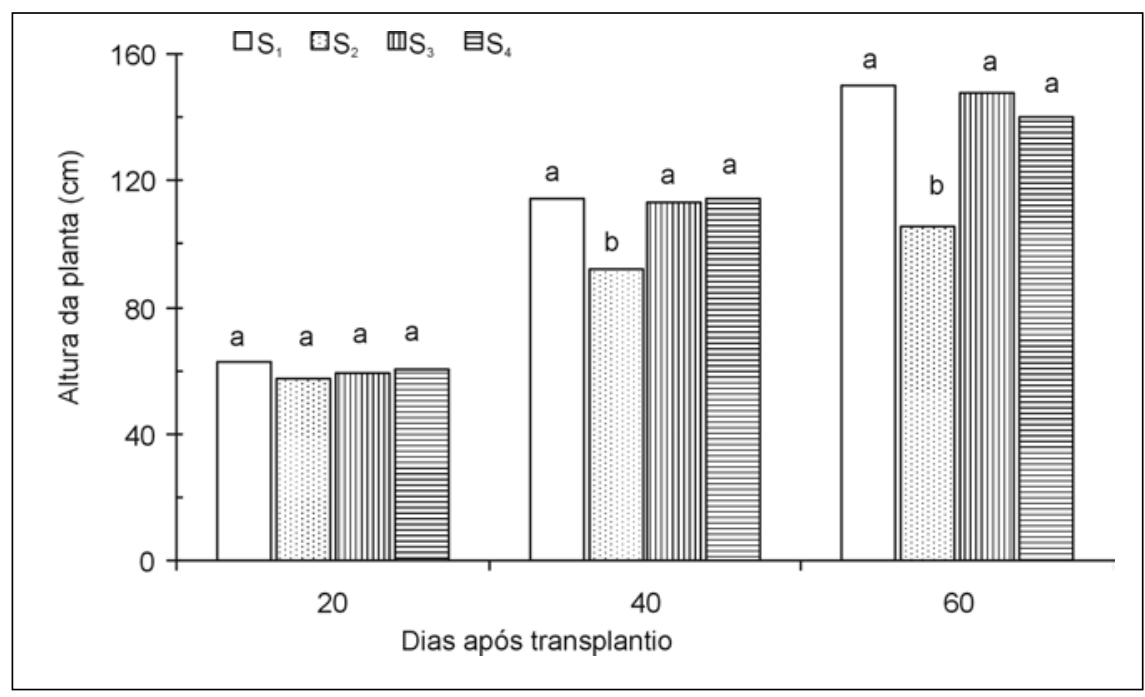

Figura 1. Efeitos de substratos sobre a altura média das plantas do tomateiro durante os 60 dias após o transplantio da cultura. Jaboticabal, FCAV/UNESP, 2000.

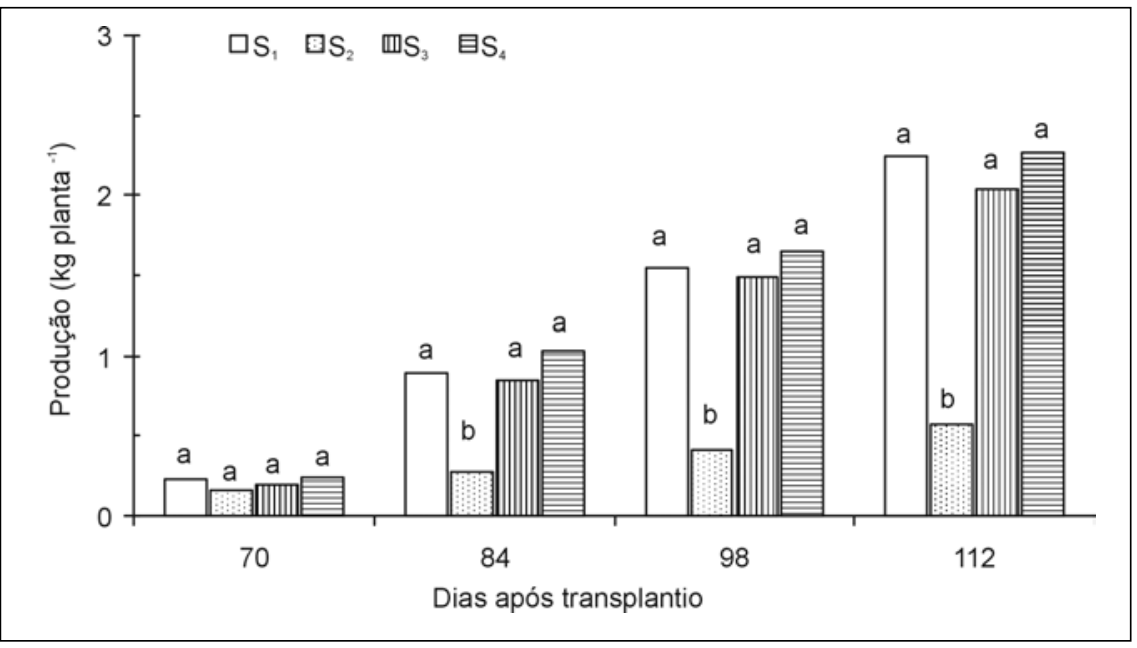

Figura 2. Efeitos de substratos sobre a produção média do tomateiro durante o período de colheita da cultura. Jaboticabal, FCAV/UNESP, 2000.

ciado pelos aumentos da lâmina de água aplicada em todas as parcelas a partir de 36 dias após o transplantio. Este reduzido crescimento vegetativo refletiu em menor número de cachos, menor número e peso dos frutos, proporcionando consequentemente produção significativamente inferior, quando comparada àquelas obtidas nos demais substratos (Figura 2).

Conforme descrito anteriormente, a estimativa da demanda de água pela cultura, com base na evaporação do tanque classe $\mathrm{A}$, não foi suficiente para suprir a necessidade hídrica das plantas após os primeiros trinta dias de desenvolvimento. Esta situação também foi descrita por Loures et al. (1998), ao es- tudar a produção de tomate cultivado em substrato comercial. Como a lâmina de água aplicada no presente trabalho foi a mesma para os quatro substratos, observou-se a ocorrência de períodos relativamente longos de encharcamento nas parcelas que continham o substrato $\mathrm{S}_{2}$. É possivel que tenha ocorrido devido à maior capacidade de retenção de água do bagaço de cana-de-açúcar, provavelmente proporcionando deficiência de oxigênio nas condições destas parcelas. Adams (1994), trabalhando com plantas de tomate desenvolvidas em cultivos com excesso de água sem aeração, observou redução de $34 \%$ de matéria seca nas plantas desenvolvidas sob excesso de água, quando comparadas àquelas desenvolvidas em ambiente apropriadamente aerado. Os pesos totais de $\mathrm{Ca}$ e $\mathrm{Mg}$ por folha foram reduzidos em mais de $50 \%$ e, a absorção de água e a maioria dos nutrientes foram reduzidos em torno de $30 \%$. Cornillon (1994) descreveu situações semelhantes e ainda observou acúmulo de ferro em toda a planta desenvolvida em substratos com baixa concentração de oxigênio. Em relação ao crescimento e à atividade radicular, um substrato deve armazenar um determinado volume de água e, ao mesmo tempo, manter teor adequado de oxigênio em torno das raízes (Salsac et al., 1997), condições que não foram satisfatórias no substrato $\mathrm{S}_{2}$.

Corroborando os resultados obtidos por Loures et al. (1998), verificou-se no presente trabalho que a estimativa da evapotranspiração, pelo método do tanque classe A, não foi eficaz para calcular as reais exigências hídricas do tomateiro cultivado em substratos sob ambiente protegido. Considerando que as coberturas plásticas criam condições bastante diferentes daquelas encontradas a céu aberto, faz-se necessário ajustar modelos de transpiração das culturas protegidas, que permitam estimar com suficiente precisão a necessidade de água a intervalos curtos de tempo em substratos específicos.

Com relação ao manejo de fertirrigação, verificou-se que o parcelamento da oferta de nutrientes à cultura desenvolvida em substrato sob ambiente protegido resultou em consideráveis melhorias de desenvolvimento e produção, visto que os nutrientes foram oferecidos de maneira mais uniforme, durante todo o ciclo da cultura.

Os substratos utilizados no presente trabalho, com exceção do $\mathrm{S}_{2}$ (areia fina + bagaço de cana-de-açúcar), apresentaram potencial de uso para a produção de tomate. Embora o substrato $\mathrm{S}_{2}$ tenha se mostrado inferior aos demais, acredita-se que, se mantido o teor de umidade próximo a sua capacidade máxima de retenção, não ocorram os problemas apresentados neste trabalho.

Diante da baixa produtividade obtida nos tratamentos avaliados, recomenda-se maiores estudos, objetivando desenvolvimento e caracterização de substratos, quantidades e/ou 
parcelamentos de nutrientes utilizados, bem como modelos para estimar as necessidades hídricas das culturas em ambientes protegidos.

\section{AGRADECIMENTOS}

À FAPESP pelo auxílio financeiro prestado ao desenvolvimento desta pesquisa e à CAPES pela bolsa concedida a Carolina Fernandes.

\section{LITERATURA CITADA}

ABAK, K.; CELIKEL, G. Comparison of some Turkish originated organic and inorganic substrates for tomato soilless culture. Acta Horticulturae, n. 366, p. 423-429, 1994.
ADAMS, P. Some effects of the environment on the nutrition of greenhouse tomatoes. Acta Horticulturae, v. 366, p. 405-416, 1994.

ANDRIOLO, J.L.; DUARTE, T.S.; LUDKE, L.; SKREBSKY, E.C. Crescimento e desenvolvimento do tomateiro cultivado em substrato com fertirrigação. Horticultura brasileira, Brasília, v. 15, n. 1, p. 28-32, 1997.

CORNILLON, P. Mineral nutrition of vegetables under protected cultivation in mild winter climate. Acta Horticulturae, v. 357, p. 63-82, 1994.

DOORENBOS, J.; KASSAN, A.H. Yield response to water. Rome: FAO, 1979. $193 \mathrm{p}$.

DOORENBOS, J.; PRUITT, W.O. Las necesidades de agua de los cultivos. Roma: FAO, 1976. $193 \mathrm{p}$.

FERNANDES, C.; CORÁ, J.E.; ARAUJO, J.A.C. Caracterização físico-hídrica de substratos utilizados no cultivo de hortaliças. Horticultura Brasileira, Brasília, v. 18, Suplemento, p. 471-473, 2000.
LOURES, J.L.; FONTES, P.C.R.; SEDIYAMA, M.A.N.; CASALI, V.W.D.; CARDOSO, A.A. Produção e teores de nutrientes no tomateiro cultivado em substrato contendo esterco de suínos. Horticultura Brasileira, Brasília, v. 16, n. 1, p. 50-55, 1998.

MAROUELLI, W.A.; SILVA, W.L.C.; SILVA, H.R. Manejo da irrigação em hortaliças. 5. ed. Brasília: Embrapa, 1996. 72 p.

MORAES, C.A.G. Hidroponia - Como cultivar tomates em sistema NFT (Técnica do fluxo laminar de nutrientes). Jundiaí: DISQ Editora, 1997. 141 p.

SALSAC, L.; CHAILLOU, S.; MOROTGAUDRY, J.; LESAINT, C.; JOLIVET, E. Nitrate and ammonium nutrition in plants. Plant Physiology and Biochemistry, v. 25, n. 6, p. 805812, 1997. 